\title{
Efficacy of intravenous versus oral iron in the treatment of anaemia in pregnancy-A comparative study
}

\author{
Roopam Singh $^{1}$, Sonia Singhal ${ }^{2}$, Shweta Saini ${ }^{3, *}$ \\ ${ }^{1} \mathrm{HOD},{ }^{2}$ Consultant, ${ }^{3}$ Final Resident, Dept. of Obstetrics and Gynaecology, Bokaro General Hospital, Bokaro, Jharkhand, India
}

*Corresponding Author:

Email: shwetasaini0207@gmail.com

\begin{abstract}
Introduction: One of the most common medical problems in pregnancy is iron deficiency anemia throughout the developing world ${ }^{1-5}$ with the burden of disease impacting in both mother and newborn. Anaemia affects nearly half of all the pregnant women in the world. Data shows that it affects approximately 52\% patients in the developing and 23\% patients in the developed world.

Materials and Methods: A prospective study conducted on pregnant women in 26 to 34 weeks of gestation which comes under inclusion criteria. Duration of the study was 18 months. 100 patients were taken 50 in each group, Blood indices such as $\mathrm{Hb}$, $\mathrm{MCV}$, serum ferritin, reticulocyte count and adverse drug reactions were compared.

Results and Conclusion: Both intravenous and oral iron supplements were associated with increment of blood indices although rise was significantly higher intravenous group. Also intravenous iron is better tolerated compared to oral group. Thus, it can be concluded that IV iron therapy is much more effective in improving iron deficiency in pregnancy than oral.
\end{abstract}

Keywords: Pregnancy, Hemoglobin, Iron sucrose, Iron deficiency anemia, Oral ferrous sulphate.

\section{Introduction}

Iron deficiency anaemia is one of the most common medical problems encountered in pregnant females all over the developing world. ${ }^{1-5}$ The disease impacts both mother and newborn. Iron deficiency anaemia affects nearly half of all the pregnant women in the world. ${ }^{6}$ Data shows that it affects approximately $52 \%$ in the developing and $23 \%$ pregnant patients in the developed world respectively.

Anaemia is estimated to contribute to $20 \%$ of all maternal death and 9 times increase of perinatal mortality. Anaemia results in rise of preterm births, IUGR, PPH, failure of lactation and increased threat of infections in postpartum period ${ }^{7}$. Thus the key element of safe motherhood is eradication of anaemia in pregnancy.

Iron sucrose appears to have the potential for reducing iron deficiency anaemia and an appropriate alternative source of iron as it overcomes the problems of compliance and absorption and has an excellent safety record equated to other intravenous iron preparations like iron dextran, iron gluconate as well as blood transfusion. ${ }^{8-9}$ Iron deficiency anaemia in pregnancy needs acute curative measures because of its related substantial morbidity and mortality.

\section{Aims and Objectives}

The purpose of study is to equate the efficacy of intravenous iron therapy to oral iron in curing anaemia of pregnancy. The objective of this study is to evaluate the safety profile, effectiveness and compliance of oral versus intravenous iron therapy for correction of anemia occurring during pregnancy.

\section{Materials and Methods}

This research study is prospective, randomized, comparative study and conducted in the Department of Obstetrics and Gynaecology, Bokaro General Hospital, a tertiary care centre in Bokaro District of Jharkhand, India. Total duration of the study was 18 months.

Eligible participants were pregnant women between the 26th and 34th weeks of pregnancy with established iron deficiency anemia who had hemoglobin levels between 7-10 $\mathrm{g} / \mathrm{dl}$ and ferritin levels less than $15 \mathrm{ng} / \mathrm{ml}$.

Patients were distributed into two groups, Group A which includes pregnant females treated with oral iron and group B including pregnant females treated with intravenous iron.

Sample size was calculated using the formula for continuous outcomes and means from a study done by Kochhar PK et al ${ }^{10}$ in 2013.

Taking the $\alpha$ at 0.05 and desired power of study is 80 percent, the sample size required is 100,50 in each group. $(\mathrm{N} 1=50 \& \mathrm{~N} 2=50)$. This method is used to compute the sample size.

Sample size is estimated with two means study.

In a study with research hypothesis viz.

Null hypothesis H0: $\mathrm{m} 1=\mathrm{m} 2$ vs.

Alternative hypothesis Ha: $\mathrm{m} 1=\mathrm{m} 2+\mathrm{d}$

Where $d$ is the difference between two means and $n 1$ and $\mathrm{n} 2$ are the sample size of group-I and group - II, such that, $\mathrm{n}-\mathrm{n} 1+\mathrm{n} 2$.

The ratio $\mathrm{r}=\mathrm{n} 1 / \mathrm{n} 2$ is considered, whenever he researcher needs unequal sample size due to various reason.

Such as ethical, cost, availability etc.

Then the entire sample size for the study is as follows Where 
$Z \alpha$ is the normal deviate at a level of significance ( $Z \alpha$ is 1.96 for $5 \%$ level of significance)

$Z 1 \beta$ is the normal deviate at $(1 \quad \beta) \%$ power with $\beta$ \%of type II error ( 0.84 at $80 \%$ power

of study)

$\mathrm{r}=\mathrm{n} 1 / \mathrm{n} 2$ is the ratio of sample size required for 2 groups.

$\delta$ is standard deviation, $\mathrm{d}$ is difference of means of 2 groups.

The total sample size for the study with $r=1$ (equal sample size)

Taking the $\alpha$ at 5\% and desired power of study as $80 \%$

We will accept a $\mathrm{p}<0.05$ as significant.

Therefore,

$v=\{(\rho+1)(Z \alpha / 2+Z \beta / 2) 2 \delta 2\} / \rho \delta 2$

$\mathrm{n}=(1+1)(1.96+0.41) 2(0.61) 2 / 1 *(1.24-0.90) 2=$

$50.472 \approx 50$

The total sample size required for the study 100 (each group contain 50 sample)

Inclusion criteria includes pregnant women between $26-34$ week of gestation, established iron deficiency anemia and $\mathrm{Hb}$ between 7-10 gm and ferritin $<20 \mathrm{ng} / \mathrm{m}$

Exclusion criteria includes serum folate and Vitamin B12 <4 pico gram and $<100 \mathrm{pgm} / \mathrm{ml}$, anemia due to other cause like malaria, multiple pregnancy, history of other blood disorders, haemoglobin less than $7 \mathrm{~g} \%$, reactions to intravenous iron sucrose and any history of blood transfusion in present pregnancy.

\section{Methodology}

The patients were designated groups randomly through computer generated tables after clarifying in detail about study proposal and written consent was taken.

Group A $(n=A)$ comprises oral ferrous sulphate group and Group B $(n=B)$ comprises intravenous iron sucrose group.
On the first visit, detailed history was taken along with proper clinical examination. A complete haemogram was done to determine pretreatment $\mathrm{Hb} \%$, mean corpuscular volume, reticulocyte count and serum ferritin. A peripheral smear was also asked to exclude non-iron deficient anaemias.

Group A received ferrous sulphate by oral route, $200 \mathrm{mg}$ having $60 \mathrm{mg}$ of elemental iron twice daily for 4weeks whereas group B received iron sucrose intravenous dose using formula $(2.4 \mathrm{x} \mathrm{Hb}$ deficit in $\mathrm{gm} \% \mathrm{x}$ body weight in kilograms). It is delivered in divided doses, $1 \mathrm{ml}$ contained $20 \mathrm{mg}$ of elemental iron. $5 \mathrm{ml}$ of it was dissolved in $100 \mathrm{ml}$ of $0.9 \%$ of normal saline and maximum of $200 \mathrm{mg}$ infusion was given. Test dose was not given. Drip was stopped and reactions were treated if any adverse reactions were noted.

On the second visit, patients were enquired regarding compliance of the therapy and clinical examination was done again. Blood sample was taken to check haemogram and the post treatment parameters were noted.

Statistical Analysis: Descriptive statistical analysis was carried out using SPSS version 17 and the data was presented as mean $+\mathrm{SD}, 95 \%$ or as percentage where appropriate. Data was also checked for normality before statistical analysis. Unpaired student t-test was used to compare normally distributed continuous variables.

\section{Results}

A total of 100 female patients of 26-34 weeks of gestation attending antenatal care were randomly distributed in two groups of 50 each. Table 1 and table 2 shows all the haematological parameters before and after treatment in intravenous group which are statistically significant.

Table 1: Showing different haematological parameters in Group A (oral iron)

\begin{tabular}{|l|c|c|c|}
\hline \multicolumn{1}{|c|}{ Parameters } & Pre treatment & Post treatment & p value \\
\hline Haemoglobin & $7.72+0.54$ & $9.71+0.59$ & $<0.05$ \\
\hline Haematocrit & $25.36+1.15$ & $28.52+1.77$ & $<0.05$ \\
\hline Mean corpuscular volume & $65.92+2.63$ & $72.48+1.96$ & $<0.05$ \\
\hline Reticulocyte count & $0.77+0.19$ & $1.82+0.41$ & $<0.05$ \\
\hline Serum ferritin & $17.56+2.74$ & $76.28+3.77$ & $<0.05$ \\
\hline
\end{tabular}

Table 2: Showing different haematological parameters in Group B (intravenous iron)

\begin{tabular}{|l|c|c|c|}
\hline Parameters & Pre treatment & Post treatment & p value \\
\hline Haemoglobin & $7.77+0.28$ & $10.34+0.62$ & $<0.05$ \\
\hline Haematocrit & $25.27+2.71$ & $32.44+1.95$ & $<0.05$ \\
\hline Mean corpuscular volume & $65.72+1.94$ & $80.6+2.10$ & $<0.05$ \\
\hline Reticulocyte count & $0.76+0.12$ & $2.02+0.27$ & $<0.05$ \\
\hline Serum ferritin & $17.78+1.05$ & $104.82+4.59$ & $<0.05$ \\
\hline
\end{tabular}


On comparing mean baseline $\mathrm{Hb}$ in oral and IV group, the results were not found to be statistically significant, this was $7.72+0.54 \mathrm{gm} / \mathrm{dl}$ in oral and $7.77+0.28 \mathrm{gm} / \mathrm{dl}$ in intravenous group respectively. 4 weeks post treatment, the mean value was $9.71+0.59$ $\mathrm{gm} / \mathrm{dl}$ and $10.34+0.62 \mathrm{gm} / \mathrm{dl}$ in oral and IV group respectively ( $\mathrm{p}$ value $<0.0001$ ), which is statistically significant. The average escalation of haemoglobin is $1.99 \mathrm{gm} / \mathrm{dl}$ and $2.57 \mathrm{gm} / \mathrm{dl}$ in oral and IV group respectively ( $\mathrm{p}$ value 0.0001)., Similar baseline haemoglobin levels were found in Kochhar et al $(7.6+0.8$ and $7.7+0.5 \mathrm{~g} / \mathrm{dl})$ whereas higher baseline levels were present in the AIRA et $\mathrm{al}^{11}(9.8+0.6$ and $9.9+0.5 \mathrm{~g} / \mathrm{dl})$ and Neeru $\mathrm{S}$ et $\mathrm{al}^{12}$ study, $(9.75+0.83$ and $9.18+0.94)$. Average rise of haemoglobin in oral and intravenous groups in different studies is compared in the table 3 .

Table 3: Showing comparison of increase in haemoglobin in oral and intravenous iron group in different studies.

\begin{tabular}{|l|c|c|}
\hline \multicolumn{1}{|c|}{ Study } & $\begin{array}{c}\text { Oral }(\mathbf{g m} / \mathbf{d L}) \\
\text { (increase in Hb after 4 weeks) }\end{array}$ & $\begin{array}{c}\text { Intravenous (gm/dL) } \\
\text { (increase in Hb after 4 weeks }\end{array}$ \\
\hline 2002, Bayoumeu F et al ${ }^{13}$ & 1.29 & 1.51 \\
\hline 2005, AI RA et al ${ }^{11}$ & 0.6 & 1.2 \\
\hline 2011, Halimi S et al ${ }^{14}$ & 1.9 & 3.4 \\
\hline 2012, Neeru S et al & 1.31 & 2.06 \\
\hline 2013, Kochhar PK et al ${ }^{10}$ & 3.1 & 5.1 \\
\hline 2016, Tandon A et al & 1.46 & 3.91 \\
\hline 2016, Garg A et al & & 1.63 \\
\hline 2015-2017 Present study & 0.8 & 2.57 \\
\hline
\end{tabular}

In oral and IV group, baseline MCV is $65.92 \mathrm{fl}+2.63$ and $65.72+2.71 \mathrm{fl}$ respectively. After 4 weeks post treatment, there was significant increase of $6.56 \mathrm{fl}$ and $14.88 \mathrm{fl}$ in oral and intravenous group respectively ( $\mathrm{p}$ value $0.0001)$.

In our research study, the mean baseline serum ferritin is $17.56+2.74 \mathrm{ng} / \mathrm{ml}$ and $7.78+1.05 \mathrm{ng} / \mathrm{ml}$ in oral and IV group respectively which increased to $76.28+3.77 \mathrm{ng} / \mathrm{ml}$ and $104.82+4.59 \mathrm{ng} / \mathrm{ml}$ in oral and IV group post treatment. Thus, there is a statistically significant rise of $58.72 \mathrm{ng} / \mathrm{ml}$ and $87.04 \mathrm{ng} / \mathrm{ml}$ respectively in oral and IV group.

Table 4: Showing comparison of various hematological parameters in group A and group B

\begin{tabular}{|l|c|c|c|}
\hline \multicolumn{1}{|c|}{ Parameters } & Group (oral iron) & Group B (IV iron) & p value \\
\hline Hemoglobin & $9.71+0.59$ & $10.34+0.62$ & 0.001 \\
\hline Hematocrit & $28.52+1.77$ & $32.44+1.95$ & 0.001 \\
\hline $\begin{array}{l}\text { Mean corpuscular volume } \\
\text { (MCV) }\end{array}$ & $72.48+1.96$ & $80.6+2.10$ & 0.001 \\
\hline Reticulocyte count & $1.82+0.41$ & $2.02+0.27$ & 0.001 \\
\hline Serum ferritin & $76.28+3.77$ & $104.82+4.59$ & 0.001 \\
\hline
\end{tabular}

In this study, the birth weight of the child born in oral and intravenous groups was not found to be statistically significant. 8 neonates had a birth weight of $<2500 \mathrm{gm}$ in oral iron treated group whereas only 3 neonates had birth weight of $<2500 \mathrm{gm}$ in intravenous iron treated group. This is comparable to the results of Kochhar et al.

\section{Conclusion}

In the present study, on comparing intravenous iron with oral iron in anemia of pregnancy, it is concluded that intravenous iron sucrose is a safe and effective substitute in treating anemia resulting in rise of hemoglobin, mean corpuscular volume level, surge in hematocrit $\%$, reticulocyte count and serum ferritin. It also has better compliance when compared to oral iron therapy.

\section{References}

1. Brabin BJ, Hakimi M, Pelletier D. An analysis of anemia and pregnancy-related maternal mortality. J Nutr. 2001 Feb;131(2S-2):604S-614S; discussion 614S-615S.

2. Murray CJL, Lopez AD. Global and regional causes of death patterns in 1990. Global comparative assessments in health sector-Disease burden, expenditures and intervention packages. 1994:21-54, WHO Geneva, Switzerland.

3. WHO. The prevalence of anaemia in women: a tabulation of available information 1992b maternal health and safe motherhood programme. Geneva, Switzerland.

4. WHO (1996) Revised 1990 estimate of maternal mortality. A new approach by WHO and UNICEF. WHO, Geneva, Switzerland.

5. Bhatt R. Maternal mortality in India, FOGSI- WHO study. J Obstet Gynecol Ind 1997;47:2.

6. UNICEFIUNOIWHO GENEVA 2001. Iron deficiency anaemia, assessment, prevention and control. 
7. Theresa OS. Iron status during pregnancy: setting the stage for mother and infant. Am J Clinc Nutr 2005:81;1218S-22S.

8. Scot BS and George MR. Parental iron therapy option. Am J 2004:76:74-8.

9. Chandler G, Harchowal J, Macdougall IC. Intravenous iron sucrose: establishing a safe dose. Am J Kidney Dis. 2001 Nov;38(5):988-91

10. Kochhar PK, Kaundal A, Ghosh P. Intravenous iron sucrose versus oral iron in treatment of iron deficiency anemia in pregnancy: a randomized clinical trial. J Obstet Gynaecol Res. 2013 Feb;39(2):504-10. doi:10.1111/j.1447-0756.2012.01982.x.

11. Al RA, Unlubilgin E, Kandemir O, Yalvac S, Cakir L, Haberal A. Intravenous versus oral iron for treatment of anemia in pregnancy: a randomized trial. Obstet Gynecol. 2005 Dec;106(6):1335-40.

12. Neeru S, Nair NS, Rai L. Iron sucrose versus oral iron therapy in pregnancy anemia. Indian J Community Med. 2012 Oct;37(4):214-8. doi:10.4103/0970-0218.103467.

13. Bayoumeu F, Subiran-Buisset C, Baka NE, Legagneur H, Monnier-Barbarino P, Laxenaire MC. Iron therapy in iron deficiency anemia in pregnancy: intravenous route versus oral route. Am J Obstet Gynecol. 2002 Mar;186(3):51822.

14. Halimi S, Ashhad Halimi SM, Shoaib M. Oral versus parenteral iron therapy for correction of iron deficiency anaemia in pregnancy. Gomal Journal of Medical Sciences. 2001Jan-June; 9(1).

15. Tandon A, Gupta V, Chaudhari P, Kumari N.

Comparison between intravenous iron sucrose versus oral iron therapy in pregnant women with nutritional anemia: a prospective study. Int J Reprod Contracept Obstet Gynecol 2016;5:2278-81.

16. Garg A, Agarwal M, Shankar U, Shetty S. Comparative study of oral iron and intravenous iron sucrose for the treatment of iron deficiency anemia in pregnancy. Int $\mathrm{J}$ Reprod Contracept Obstet Gynecol 2017;6:172-5. 